\title{
Cannabisarzneimittel
}

\section{Fahrverbot auch Tage nach THC-Konsum}

\author{
Per Gesetz ist seit März 2017 der Einsatz von Cannabisarzneimitteln als \\ Therapiealternative zugelassen. Autofahrer sollten ärztlicherseits auf \\ die Eigenschaften des Cannabiswirkstoffs hingewiesen werden.
}

C annabiskonsumenten dürfen auch noch ein oder zwei Tage später nicht einfach wieder Auto fahren. Sie müssen immer sichergehen, dass ihr Blut keine erhöhte Konzentration des Cannabiswirkstoffs Tetrahydrocannabi-

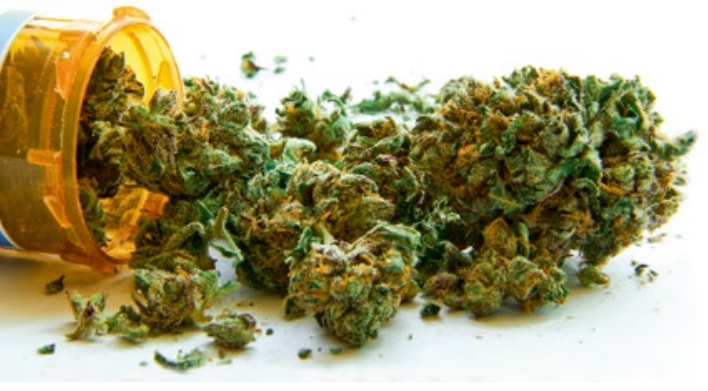

nol (THC) mehr enthält, befand jetzt der Bundesgerichtshof (Az.: 4 StR 422/15). Ärzte sollten Patienten daher zunächst entsprechend beraten, wenn sie die Cannabisarznei anwenden. Zudem könnte es zu Rückfragen in der Sprechstunde kommen, denn Cannabiskonsumenten sollen laut BGH bei Bedarf auch „fachkundigen Rat" einholen. Bei Medikamenten verhalte es sich ja nicht anders, so die Richter, ohne allerdings ausdrücklich auf THC-haltige Arzneimittel einzugehen.

Gerichte und Behörden gehen in Deutschland von einem Grenzwert von 1,0 Nanogramm THC je Milliliter Blutserum aus. Eine Empfehlung der Grenz- wertkommission, den Wert anzuheben, wird bislang noch nicht umgesetzt. Der Wert von 1,0 Nanogramm kann je nach Veranlagung und Konsumverhalten aber auch noch nach mehrtägiger Cannabisabstinenz erreicht werden. Daher war unter den Zivilgerichten umstritten, ob ein Verstoß auch dann ohne Weiteres sanktioniert werden kann, wenn der Cannabiskonsum bereits mehrere Tage zurückliegt. Dies hat der Bundesgerichtshof nun bejaht. Konsumenten wüssten um die möglichen Wirkungen der Droge. Ehe sie sich wieder ans Steuer setzten, müssten sie sich einer „gehörigen Selbstprüfung" unterziehen und bei Bedarf auch „fachkundigen Rat" einholen. Soweit ein Cannabiskonsument keine Gewissheit über seine Fahrtauglichkeit erlangen kann, ,ist er gehalten, von der Fahrt Abstand zu nehmen", heißt es in dem jetzt veröffentlichten Karlsruher Beschluss. Martin Wortmann

\section{Studie: Studium der Medizin ist lukrativ}

Je höher der Bildungsabschluss, desto größer ist im Schnitt das Einkommen, so das Ergebnis einer kürzlich durchgeführten Analyse des Ifo-Institutes in Frankfurt. Wie hoch sind da heutzutage die Differenzen?

B esonders das Medizinstudium zahlt sich im Nachhinein betrachtet aus: Es bringt einem Mann über das gesamte Erwerbsleben im Schnitt bis zu 983.000€ mehr Einkommen als eine Lehre. Bei Frauen sind es 612.731€. Das ist Ergebnis einer Analyse des Ifo-Institutes im Auftrag der Fondsgesellschaft Union Investment. Der Studie zufolge bringt jeder höhere Abschluss über das gesamte Erwerbsleben nach Abzug der Kosten in Deutschland zwischen $22 \%$ und $64 \%$ mehr Einkommen. Zugleich senkt Bildung das Risiko der Arbeitslosigkeit deutlich „und ist daher die beste Arbeitslosenversicherung“, so der Studien- autor Ludger Wößmann vom Ifo-Institut in Frankfurt.

Laut Angaben liegt das Lebenseinkommen mit einer abgeschlossenen Lehre im Schnitt $143.000 €$ netto über dem von Menschen ohne Berufsausbildung. Gegenüber einer Ausbildung erzielt ein Meister oder Techniker durchschnittlich $129.000 €$ netto mehr, ein Fachhochschulabsolvent kommt auf ein Plus von $267.000 €$ und ein Universitätsabsolvent von $387.000 €$.

Indes gibt es große Unterschiede zwischen Studiengängen und Geschlechtern: Sozialarbeit schlägt nur mit einem Plus von knapp $20.000 € \mathrm{zu}$ Buche. Bei

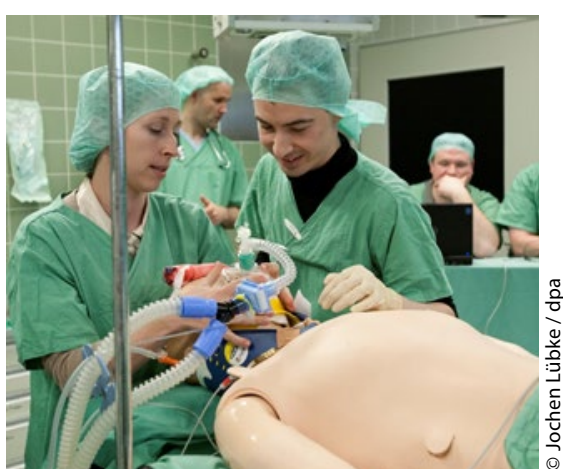

Insbesondere das Medizinstudium zahlt sich im späteren Erwerbsleben aus.

Frauen sind es hier 79.000€. Bei Kunstund Kunstwissenschaften, im Lehramt außerhalb von Gymnasien und Berufsschulen sowie einigen anderen Studiengängen erzielen Frauen ebenfalls höhere Lebenseinkommensgewinne als Männer. 